\title{
Endoscopic Retrograde Cholangiopancreatography in Patients With Versus Without Prior Myocardial Infarction or Coronary Revascularization: A Nationwide Cohort Study
}

Harsh K. Patel ${ }^{1}$, Rupak Desai ${ }^{2}$, Shreyans Doshi ${ }^{3}$, Mohammad Haider ${ }^{4}$, Neet Lakhani ${ }^{5}$, Falah Abu Hassan ${ }^{6}$, Rajkumar Doshi ${ }^{7}$, Viveksandeep Thoguluva Chandrasekar ${ }^{8}$

1. Internal Medicine, Ochsner Clinic Foundation, New Orleans, USA 2. Cardiology, Atlanta Veterans Affairs Medical Center, Decatur, USA 3. Gastroenterology, Medical College of Georgia, Augusta University, Augusta, USA 4. Internal Medicine, NewYork-Presbyterian Brooklyn Methodist Hospital, Brooklyn, USA 5. Internal Medicine, Baroda Medical College, The Maharaja Sayajirao University of Baroda, Vadodara, IND 6. Surgery, Princess of Wales Hospital, Bridgend, GBR 7. Internal Medicine, University of Nevada, Reno School of Medicine, Reno, USA 8. Gastroenterology, Mayo Clinic in Arizona, Scottsdale, USA

Corresponding author: Rupak Desai, drrupakdesai@gmail.com

\section{Abstract}

\section{Background}

Endoscopic retrograde cholangiopancreatography (ERCP) can be associated with complications, including precipitation of peri-procedural myocardial ischemia. However, data regarding the trends and impact of previous myocardial infarction (MI) and/or percutaneous coronary intervention (PCI) or coronary artery bypass grafting (CABG) on ERCP outcomes remains unknown.

\section{Methods}

Using the National Inpatient Sample (2007-2014) and relevant ICD-9-CM codes, we identified adults who underwent ERCP with (Group 1) and without (Group 2) prior history of MI/PCI/CABG, and compared their demographics, comorbidities, and inpatient outcomes. Primary endpoints were inpatient mortality and post-ERCP complications. The secondary endpoints were discharge disposition, the mean length of stay, and total hospital charges.

\section{Results}

Of 1,374,773 ERCP procedures performed, 120,418 (8.8\%) were performed in adult patients with a prior history of MI/PCI/CABG with an increasing trend from 2007-2014 (7.5\% to $9.5 \%$, $\mathrm{p}_{\text {trend }}=0.022$ ). Group 1 consisted of older, white, males compared to Group 2. Group 1 demonstrated a higher prevalence of all-

Review began 03/07/2021 Review ended 03/12/2021 Published 03/16/2021

\section{๑) Copyright 2021}

Patel et al. This is an open access article distributed under the terms of the Creative Commons Attribution License CC-BY 4.0., which permits unrestricted use, distribution, and reproduction in any medium, provided the original author and source are credited. cause mortality ( $1.7 \%$ vs. $1.5 \%$, p $<0.001)$, other cardiovascular comorbidities, post-ERCP cardiopulmonary complications (5.6\% vs. $3.8 \%$, p<0.001), sepsis ( $10.2 \%$ vs. $8.2 \%$, p<0.001) and hemorrhage $(1.5 \%$ vs. $1.2 \%$, $\mathrm{p}<0.001)$ as compared to Group 2. However, post-ERCP pancreatitis $(14.1 \%$ vs. $15.4 \%, \mathrm{p}<0.001)$ was lower in Group 1 without any difference in frequency of cholecystitis $(0.4 \%$ vs. $0.4 \%, p=0.180)$. The mean length of stay was marginally higher in Group 1, without any difference in the hospitalization charges between the groups.

\section{Conclusions}

This nationwide study revealed higher inpatient mortality, sepsis, and hemorrhage in adult patients who underwent ERCP with a prior history of MI/PCI/CABG.

Categories: Cardiology, Internal Medicine, Gastroenterology

Keywords: endoscopic retrograde cholangiopancreatography, ercp, myocardial ischemia, myocardial infarction, coronary artery disease, percutaneous coronary intervention, coronary artery bypass grafting

\section{Introduction}

Endoscopic retrograde cholangiopancreatography (ERCP) has been increasingly performed in all age groups is the management of choice for many pancreaticobiliary pathologies. It helps to avoid the need for emergent highly invasive surgeries as it is a minimally invasive procedure with significantly less morbidity and mortality. However, there is limited data on the effect of the presence of comorbidities and outcomes in patients undergoing ERCP. Longer procedure time and the use of general anesthesia in patients with multiple co-morbidities and cholangitis puts them at higher risk of cardiovascular-related morbidity due to 
ERCP when compared to other GI endoscopic procedures [1,2]. Besides, increasing the use of ERCP as a therapeutic intervention compared to a diagnostic modality makes it essential to assess the appropriateness of its use in patients with a prior history of myocardial infarction (MI), percutaneous coronary intervention (PCI), or coronary artery bypass grafting (CABG).

There is a dearth of literature on the utilization of ERCP in patients with comorbid cardiovascular conditions. Little is known about those trends in recent years and how an ERCP affects the hospitalization outcomes in those patients. This national database study aimed to retrospectively identify the trends and compare outcomes in patients with a prior history of MI, PCI, or CABG who underwent inpatient ERCP as compared to those having no such comorbidities.

\section{Materials And Methods \\ Data source}

The National Inpatient Sample (NIS) 2007-2014, created by the Agency for Healthcare Research and Quality for Healthcare Cost and Utilization Project (HCUP), was queried to examine the study cohort [3]. The NIS is a publicly available all-payer inpatient dataset in the United States, which comprises a stratified sample of $20 \%$ nonfederal US community hospitals. Over $95 \%$ of the US population is embodied by this weighted dataset, which provides nationwide estimates of over 35 million hospitalizations each year. The NIS contains patient-level information including demographics, discharge diagnoses (one primary and 24 secondary diagnoses), in-hospital procedures (one primary and 14 secondary procedures), hospital-level features such as ownership, bed size, teaching status, urban/rural setting, and geographical region of hospitals. Resource utilization, such as mean length of stay (LOS), total hospitalization charges, and disposition are likewise consolidated into this dataset. An Institutional Review Board validation is not mandatory since the NIS dataset does not encase patient identifiers.

\section{Study population}

We examined ERCP-related hospitalizations in adult patients using ICD-9 CM procedure codes (51.10, 51.11, $52.13,52.14,52.21,51.64,52.92,52.93,52.94,52.97,52.98,51.14,51.88,51.87,51.86,51.85$, and 51.84) after excluding missing cases. A comorbid history of prior MI, PCI, or CABG cases was identified using the ICD-9 CM codes 412, V45.82, V45.81, respectively. Secondary discharge diagnoses were sought to evaluate ERCPrelated complications by the relevant ICD-9 CM codes as validated and used in the previous studies [4]. We compared mortality outcomes in patients with a prior history of MI, PCI, or CABG as compared to those without such comorbidities

\section{Study variables}

We studied patient-level demographics including age, sex, race, type of admission, the day of admission, insurance payer type, median household income percentile, hospital-level characteristics including hospital ownership, bed size location/teaching status and region of hospital and hospitalization outcomes such as inhospital mortality, LOS, total hospital charges and discharge disposition. We also incorporated cardiopulmonary comorbidities, post-ERCP pancreatitis, perforation, hemorrhage, and sepsis in our analysis from the secondary discharge diagnoses.

\section{Outcomes}

The primary endpoint was the trends in the ERCP procedures being performed in patients with a past medical history of MI, PCI, or CABG, and in-hospital mortality. The secondary endpoint was post-ERCP adverse events, mean LOS, hospital charges, and disposition of patients with and without a prior history of $\mathrm{MI} / \mathrm{PCI} / \mathrm{CABG}$ in patients undergoing ERCP.

\section{Statistical analyses}

By applying sampling discharge weights to assess national estimates, we used the Pearson's chi-square test and Student's t-test to compare the categorical and continuous variables between the cohorts. Results were expressed in percentages and mean $\pm \mathrm{SD}$, respectively. We also evaluated predictors of in-hospital complications using a multivariable regression model that was adjusted for demographics, hospital characteristics, and baseline comorbidities. A two-tailed p-value $<0.05$ was used as the margin for the statistical significance. Statistical Package for the Social Sciences (SPSS) version 22 (IBM Corp., Armonk, NY) was used to perform all statistical analyses.

\section{Results}

A total of 1,372,773 hospitalizations with (mean age $59.4 \pm 19.8$ years, $60.1 \%$ males) ERCP procedures were identified from discharge diagnosis between 2007 and 2014. Among them, 120,418 (8.8\%) patients had a prior history of MI (3.7\%), PCI (3.3\%), or CABG (3.9\%) (Group 1). The remaining cohort of patients was named Group 2. 


\section{Cureus}

There was an increasing trend in ERCP use in Group 1 from 2007 to 2014 ( $7.5 \%$ to 9.5\%, ptrend=0.022). At the same time, inpatient mortality in Group 1 decreased from 2007 to 2014 (1.8\% to $1.4 \%, p_{\text {trend }}=0.0147$ ) (Figure $1)$.

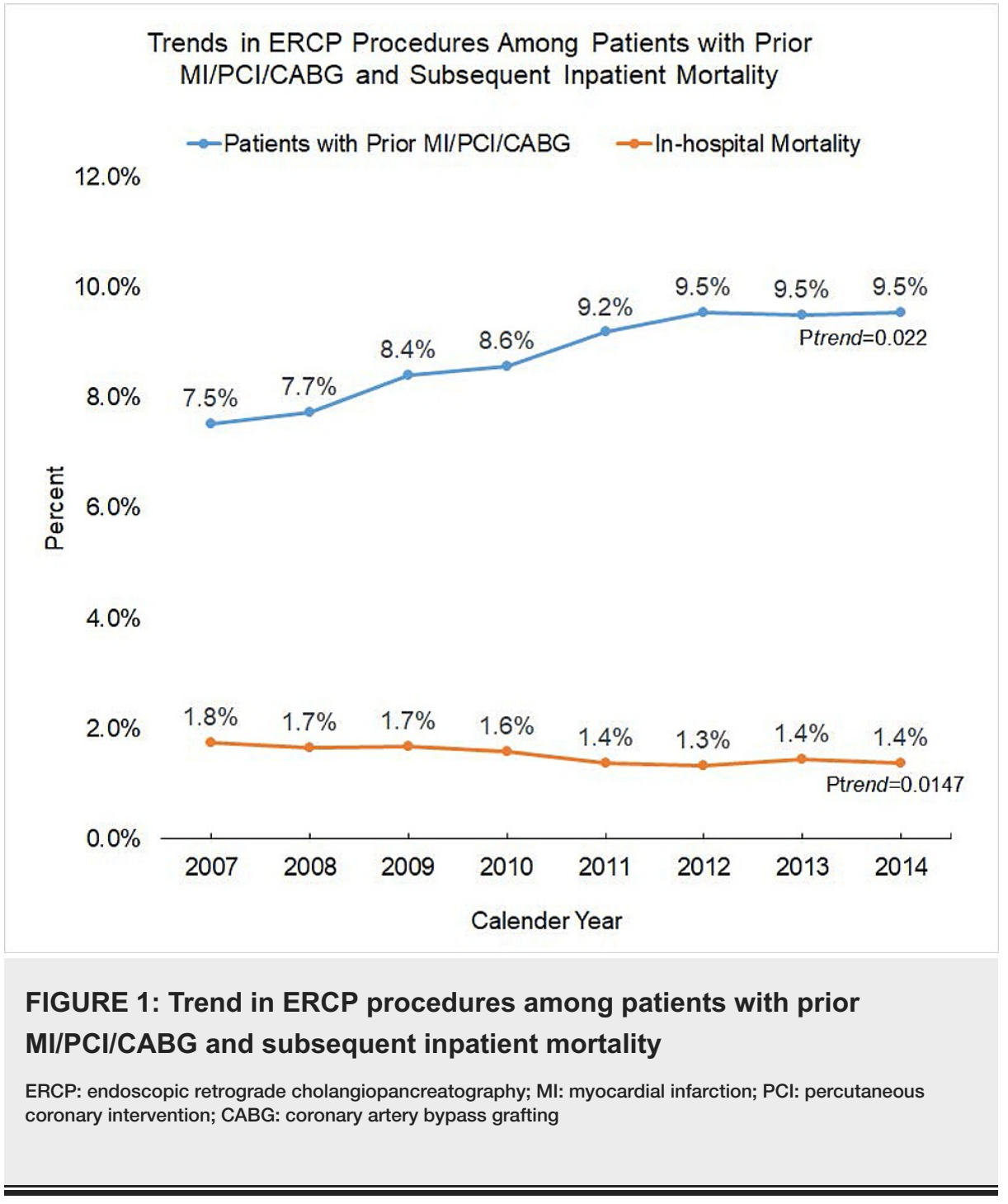

Table 1 presents the baseline characteristics of both groups. Group 1 cohort was relatively older (mean age 74 years vs. 58 years, $\mathrm{p}<0.001)$; had a higher proportion of the males $(63.9 \%)$ compared to a higher proportion of the females $(62.4 \%)$ in the Group 2 cohort ( $\mathrm{p}<0.001)$; and mainly consisted of white $(82 \%)$ patients. Patients in Group 2 had a higher proportion of patients of African American (9.4\% vs. 5.4\% p $<0.001)$ and Hispanic $(16.1 \%$ vs. $7.1 \%, p<0.001)$ ethnicity. There were statistically significant results but both groups were clinically comparable with respect to the type of admission (elective vs. nonelective), median household income, and bed size, the region as well as the location of the hospital.

\begin{tabular}{|c|c|c|c|c|}
\hline \multirow{2}{*}{ Variable } & \multicolumn{2}{|c|}{ Prior History of MI/PCl/CABG } & \multirow[b]{2}{*}{$\begin{array}{l}\text { Overall }(n=1,374,773 \\
\text { ) }\end{array}$} & \multirow{2}{*}{ p-Value } \\
\hline & $\begin{array}{l}\text { No (Group 2) (n= } \\
1,254,356)\end{array}$ & $\begin{array}{l}\text { Yes (Group 1) } \\
(n=120,418)\end{array}$ & & \\
\hline Age (years) at hospitalization & & & & $<0.001$ \\
\hline Mean $\pm S D$ & $58.0 \pm 19.9$ & $74.0 \pm 11.2$ & $59.4 \pm 19.8$ & \\
\hline $18-44$ years & $27.0 \%$ & $1.0 \%$ & $24.7 \%$ & \\
\hline 45-64 years & $31.5 \%$ & $18.7 \%$ & $30.4 \%$ & \\
\hline$\geq 65$ years & $41.5 \%$ & $80.3 \%$ & $44.9 \%$ & \\
\hline Sex & & & & $<0.001$ \\
\hline
\end{tabular}




\section{Cureus}

\begin{tabular}{|c|c|c|c|c|}
\hline Male & $37.6 \%$ & $63.9 \%$ & $39.9 \%$ & \\
\hline Female & $62.4 \%$ & $36.1 \%$ & $60.1 \%$ & \\
\hline Race & & & & $<0.001$ \\
\hline White & $66.7 \%$ & $82.0 \%$ & $68.1 \%$ & \\
\hline African American & $9.4 \%$ & $5.4 \%$ & $9.1 \%$ & \\
\hline Hispanic & $16.1 \%$ & $7.1 \%$ & $15.3 \%$ & \\
\hline Asian or Pacific Islander & $3.6 \%$ & $2.5 \%$ & $3.5 \%$ & \\
\hline Native American & $0.6 \%$ & $0.6 \%$ & $0.6 \%$ & \\
\hline Others & $3.5 \%$ & $2.5 \%$ & $3.4 \%$ & \\
\hline Non-elective admission & $87.3 \%$ & $88.1 \%$ & $87.3 \%$ & $<0.001$ \\
\hline $\begin{array}{l}\text { Median household income national } \\
\text { quartile }\end{array}$ & & & & $<0.001$ \\
\hline $0-25$ th & $26.1 \%$ & $24.4 \%$ & $26.0 \%$ & \\
\hline 26-50th & $25.6 \%$ & $26.6 \%$ & $25.7 \%$ & \\
\hline 51-75th & $25.4 \%$ & $25.0 \%$ & $25.4 \%$ & \\
\hline 76-100th & $22.8 \%$ & $24.0 \%$ & $22.9 \%$ & \\
\hline Primary expected payer & & & & $<0.001$ \\
\hline Medicare & $42.3 \%$ & $78.3 \%$ & $45.5 \%$ & \\
\hline Medicaid & $13.0 \%$ & $3.8 \%$ & $12.2 \%$ & \\
\hline Private including $\mathrm{HMO}$ & $33.7 \%$ & $14.8 \%$ & $32.1 \%$ & \\
\hline Self-pay/no charge/others & $41.5 \%$ & $16.4 \%$ & $39.3 \%$ & \\
\hline Bed size of hospital & & & & $<0.001$ \\
\hline Small & $9.9 \%$ & $9.4 \%$ & $9.8 \%$ & \\
\hline Medium & $24.2 \%$ & $23.6 \%$ & $24.1 \%$ & \\
\hline Large & $65.9 \%$ & $67.0 \%$ & $66.0 \%$ & \\
\hline Location/teaching status of hospital & & & & $<0.001$ \\
\hline Rural & $5.6 \%$ & $5.9 \%$ & $5.6 \%$ & \\
\hline Urban non-teaching & $40.0 \%$ & $40.3 \%$ & $40.0 \%$ & \\
\hline Urban teaching & $54.5 \%$ & $53.8 \%$ & $54.4 \%$ & \\
\hline Region of hospital & & & & $<0.001$ \\
\hline Northeast & $19.6 \%$ & $20.9 \%$ & $19.8 \%$ & \\
\hline Midwest & $22.1 \%$ & $25.0 \%$ & $22.4 \%$ & \\
\hline South & $35.2 \%$ & $35.5 \%$ & $35.2 \%$ & \\
\hline West & $23.0 \%$ & $18.6 \%$ & $22.7 \%$ & \\
\hline
\end{tabular}

TABLE 1: Baseline characteristics of patients undergoing ERCP with vs. without prior history of $\mathrm{MI}, \mathrm{PCl}$, or CABG

$\mathrm{P}<0.05$ indicates statistical significance.

ERCP: endoscopic retrograde cholangiopancreatography; MI: myocardial infarction; PCI: percutaneous coronary intervention; CABG: coronary artery bypass grafting; $\mathrm{HMO}$ : health maintenance organization 
Table 2 presents comorbidities in adult patients undergoing ERCP in Group 1 vs. Group 2. Comorbidities such as iron-deficiency anemia ( $21.8 \%$ vs. $17.0, \mathrm{p}<0.001)$, congestive heart failure $(20.2 \%$ vs. $5.8 \%, \mathrm{p}<0.001)$, chronic pulmonary disease ( $21.6 \%$ vs. $13.3 \%$, $\mathrm{p}<0.001)$, coagulopathy $(8.3 \%$ vs. $6.1 \%, \mathrm{p}<0.001)$, uncomplicated diabetes ( $33.7 \%$ vs. $17.6 \%$, p<0.001), diabetes with complications ( $6.0 \%$ vs. $2.6 \%$, $p<0,001)$, hypertension ( $79.6 \%$ vs. $46.6 \%$, p $<0.001$ ), dyslipidemia $(57.2 \%$ vs. $22.2 \%$, $\mathrm{p}<0.001)$, peripheral vascular disorder ( $12.8 \%$ vs. $3.3 \%$, $\mathrm{p}<0.001)$, renal failure $(18.3 \%$ vs. $7.4 \%, \mathrm{p}<0.001)$ and valvular disorder $(10.3 \%$ vs. $3.2 \%, \mathrm{p}<0.001$ ) were higher in patients in Group 1 compared to those in Group 2.

\begin{tabular}{|c|c|c|c|c|c|}
\hline \multirow{3}{*}{$\begin{array}{l}\text { Comorbidities } \\
\text { Alcohol abuse }\end{array}$} & \multicolumn{4}{|c|}{ Prior History of $\mathrm{MI} / \mathrm{PCl} / \mathrm{CABG}$} & \multirow{3}{*}{$\begin{array}{l}\text { p-Value } \\
<0.001\end{array}$} \\
\hline & \multicolumn{2}{|c|}{ No $(n=1,254,356)$} & \multicolumn{2}{|c|}{ Yes $(n=120,418)$} & \\
\hline & 51499 & $(4.1 \%)$ & 3508 & $(2.9 \%)$ & \\
\hline Deficiency anemias & 213258 & $(17.0 \%)$ & 26280 & $(21.8 \%)$ & $<0.001$ \\
\hline Congestive heart failure & 72137 & $(5.8 \%)$ & 24372 & $(20.2 \%)$ & $<0.001$ \\
\hline Chronic pulmonary disease & 166597 & $(13.3 \%)$ & 26002 & $(21.6 \%)$ & $<0.001$ \\
\hline Coagulopathy & 76418 & $(6.1 \%)$ & 9954 & (8.3\%) & $<0.001$ \\
\hline Diabetes, uncomplicated & 221333 & $(17.6 \%)$ & 40543 & $(33.7 \%)$ & $<0.001$ \\
\hline Diabetes with chronic complications & 32499 & $(2.6 \%)$ & 7182 & $(6.0 \%)$ & $<0.001$ \\
\hline Hypertension & 583926 & $(46.6 \%)$ & 95838 & $(79.6 \%)$ & $<0.001$ \\
\hline Hypothyroidism & 134200 & $(10.7 \%)$ & 17539 & (14.6\%) & $<0.001$ \\
\hline Liver disease & 68177 & $(5.4 \%)$ & 4956 & $(4.1 \%)$ & $<0.001$ \\
\hline Fluid and electrolyte disorders & 358674 & $(28.6 \%)$ & 37236 & $(30.9 \%)$ & $<0.001$ \\
\hline Metastatic cancer & 46059 & $(3.7 \%)$ & 3573 & $(3.0 \%)$ & $<0.001$ \\
\hline Dyslipidemia & 278435 & $(22.2 \%)$ & 68826 & $(57.2 \%)$ & $<0.001$ \\
\hline Smoking & 264298 & $(21.1 \%)$ & 34487 & $(28.6 \%)$ & $<0.001$ \\
\hline Obesity & 156619 & $(12.5 \%)$ & 12233 & $(10.2 \%)$ & $<0.001$ \\
\hline Peripheral vascular disorders & 41291 & $(3.3 \%)$ & 15444 & $(12.8 \%)$ & $<0.001$ \\
\hline Pulmonary circulation disorders & 20206 & $(1.6 \%)$ & 3930 & $(3.3 \%)$ & $<0.001$ \\
\hline Renal failure & 92320 & (7.4\%) & 22074 & (18.3\%) & $<0.001$ \\
\hline Valvular disease & 40609 & $(3.2 \%)$ & 12457 & $(10.3 \%)$ & $<0.001$ \\
\hline
\end{tabular}

TABLE 2: Comorbidities in adult patients undergoing ERCP with vs. without prior history of MI, $\mathrm{PCl}$, or CABG

$\mathrm{P}<0.05$ indicates statistical significance.

ERCP: endoscopic retrograde cholangiopancreatography; MI: myocardial infarction; PCI: percutaneous coronary intervention; CABG: coronary artery bypass grafting

In a bivariate analysis of two groups (Table 3), patients in Group 1 had higher inpatient mortality (1.7\% vs. $1.5 \%, \mathrm{p}<0.001)$, cardiopulmonary events ( $5.6 \%$ vs. $3.8 \%, \mathrm{p}<0.001)$, hemorrhage $(1.5 \%$ vs. $1.2 \%, \mathrm{p}<0.001)$ and sepsis $(10.2 \%$ vs. $8.2 \%, \mathrm{p}<0.001)$ compared to those in Group 2 . However, Group 1 reported a lower rate of post-ERCP pancreatitis (PEP) (14.1\% vs. $15.4 \%, \mathrm{p}<0.001)$ compared to Group 2 . There was no significant difference in presence of concomitant post-ERCP cholecystitis $(0.4 \%$ vs. $0.4 \%, \mathrm{p}=0.18)$ between the two groups. 


\section{Cureus}

\begin{tabular}{|c|c|c|c|c|c|}
\hline \multirow{3}{*}{$\begin{array}{l}\text { Outcomes } \\
\text { In-hospital mortality }\end{array}$} & \multicolumn{4}{|c|}{ Prior History of MI/PCI/CABG } & \multirow{3}{*}{$\begin{array}{l}\text { p-Value } \\
<0.001\end{array}$} \\
\hline & \multicolumn{2}{|c|}{ No $(n=1,254,356)$} & \multicolumn{2}{|c|}{ Yes $(n=120,418)$} & \\
\hline & 18888 & $(1.5 \%)$ & 2099 & $(1.7 \%)$ & \\
\hline Post-ERCP cardiopulmonary complications & 47233 & (3.8\%) & 6749 & $(5.6 \%)$ & $<0.001$ \\
\hline Post-ERCP pancreatitis & 193275 & $(15.4 \%)$ & 16976 & $(14.1 \%)$ & $<0.001$ \\
\hline Post-ERCP cholecystitis & 4740 & $(0.4 \%)$ & 485 & $(0.4 \%)$ & 0.180 \\
\hline Post-ERCP perforation & 1903 & $(0.2 \%)$ & 127 & $(0.1 \%)$ & $<0.001$ \\
\hline Post-ERCP hemorrhage & 15318 & $(1.2 \%)$ & 1802 & $(1.5 \%)$ & $<0.001$ \\
\hline Post-ERCP sepsis & 102593 & (8.2\%) & 12282 & $(10.2 \%)$ & $<0.001$ \\
\hline Disposition of patient & & & & & $<0.001$ \\
\hline Routine & 960775 & $(76.6 \%)$ & 79345 & $(65.9 \%)$ & \\
\hline Transfer to short-term hospital & 27438 & $(2.2 \%)$ & 2815 & $(2.3 \%)$ & \\
\hline Other transfers (SNF, ICF, other) & 117898 & $(9.4 \%)$ & 17434 & $(14.5 \%)$ & \\
\hline Home health care & 122789 & $(9.8 \%)$ & 18255 & $(15.2 \%)$ & \\
\hline Length of stay mean [SD] & \multicolumn{2}{|c|}{6.6 [SD 7.6] days } & \multicolumn{2}{|c|}{6.8 [SD 5.8] days } & $<0.001$ \\
\hline Total hospital charges Mean & \multicolumn{2}{|l|}{$\$ 60,142$} & \multicolumn{2}{|c|}{$\$ 60,067$} & 0.700 \\
\hline
\end{tabular}

\section{TABLE 3: Outcomes in adult patients undergoing ERCP with vs. without prior history of $\mathrm{MI}, \mathrm{PCI}$,}

or CABG

$\mathrm{P}<0.05$ indicates clinical significance.

ERCP: endoscopic retrograde cholangiopancreatography; MI: myocardial infarction; PCI: percutaneous coronary intervention; CABG: coronary artery bypass grafting; SNF: skilled nursing facility; ICF: intermediate care facility

Patients undergoing ERCP in Group 1 were more likely to be discharged to short-term hospitals (2.3\% vs. $2.2 \%, \mathrm{p}<0.001)$, skilled nursing facility or intermediate care facility ( $14.5 \%$ vs. $9.4 \%, \mathrm{p}<0.001)$, and home health care $(15.2 \%$ vs. $9.8 \%$, $\mathrm{p}<0.001)$ compared to Group 2 . However, patients in Group 1 also demonstrated higher average LOS (6.8 days vs. 6.6 days, $p<0.001$ ) but without any difference in the mean hospitalization charges $(\$ 60,067$ vs. $\$ 60,142, \mathrm{p}=0.700)$.

In a multivariable analysis for predictors of in-hospital complications (Table 4), patients with age >45 years, gender, races other than caucasian, admission at an urban facility or on a weekend, hospitals in the western United States, and prior comorbidities like chronic obstructive pulmonary disease, coagulopathy, congestive heart failure or valvular heart disease, fluid and electrolyte disorders, lymphoma, obesity, renal failure and solid tumor without metastasis were independently associated with higher odds of any complications $(\mathrm{p}<0.05)$. Patients admitted at a facility in the southern United States, when Medicaid was the primary payor, with known alcohol abuse, depression or psychosis, hypertension, and hypothyroidism were independently associated with lower odds of any complications during ERCP-related admission $(\mathrm{p}<0.05)$.

Predictors

Age (years) at admission

18-44 years

45-64 years

$\geq 65$ years

Male vs. Female sex

\begin{tabular}{l|l|}
\hline Adjusted OR & $95 \% \mathrm{Cl}$ \\
\hline & Lower Upper
\end{tabular}

p-Value

$<0.001$

Referent

$\begin{array}{llll}1.25 & 1.07 & 1.47 & 0.005 \\ 1.51 & 1.29 & 1.77 & <0.001 \\ 1.08 & 1.04 & 1.11 & <0.001\end{array}$




\section{Cureus}

\begin{tabular}{|c|c|c|c|c|}
\hline \multicolumn{5}{|l|}{ Race } \\
\hline White & \multicolumn{3}{|l|}{ Referent } & $<0.001$ \\
\hline African American & 1.00 & 0.93 & 1.06 & 0.885 \\
\hline Hispanic & 1.11 & 1.06 & 1.18 & $<0.001$ \\
\hline Asian or Pacific Islander & 1.18 & 1.08 & 1.28 & $<0.001$ \\
\hline Native American & 1.07 & 0.88 & 1.29 & 0.505 \\
\hline Others & 1.32 & 1.21 & 1.44 & $<0.001$ \\
\hline Non-elective vs. Elective admission & 1.44 & 1.37 & 1.51 & $<0.001$ \\
\hline Bed size of the hospital & & & & 0.478 \\
\hline Small & \multicolumn{4}{|l|}{ Referent } \\
\hline Medium & 1.02 & 0.97 & 1.07 & 0.504 \\
\hline Large & 1.03 & 0.98 & 1.08 & 0.251 \\
\hline Location/teaching status of the hospital & & & & $<0.001$ \\
\hline Rural & \multicolumn{4}{|l|}{ Referent } \\
\hline Urban non-teaching & 1.13 & 1.06 & 1.21 & $<0.001$ \\
\hline Urban teaching & 1.19 & 1.12 & 1.27 & $<0.001$ \\
\hline Region of hospital & & & & $<0.001$ \\
\hline Northeast & \multicolumn{4}{|l|}{ Referent } \\
\hline Midwest & 1.02 & 0.98 & 1.06 & 0.407 \\
\hline South & 0.94 & 0.90 & 0.97 & 0.001 \\
\hline West & 1.10 & 1.06 & 1.15 & $<0.001$ \\
\hline Primary expected payer & & & & $<0.001$ \\
\hline Medicare & \multicolumn{4}{|l|}{ Referent } \\
\hline Medicaid & 0.88 & 0.81 & 0.95 & 0.002 \\
\hline Private including health maintenance organization & 1.02 & 0.97 & 1.07 & 0.408 \\
\hline Median household income national quartile for patient ZIP code & & & & $<0.001$ \\
\hline 0-25th & \multicolumn{4}{|l|}{ Referent } \\
\hline 26-50th & 0.98 & 0.94 & 1.01 & 0.209 \\
\hline 51-75th & 0.99 & 0.95 & 1.03 & 0.621 \\
\hline 76-100th & 0.91 & 0.88 & 0.95 & $<0.001$ \\
\hline Weekend vs. weekday admission & 1.15 & 1.11 & 1.18 & $<0.001$ \\
\hline \multicolumn{5}{|l|}{ Comorbidities } \\
\hline Acquired immune deficiency syndrome & 1.42 & 0.91 & 2.22 & 0.119 \\
\hline Alcohol abuse & 0.89 & 0.81 & 0.97 & 0.005 \\
\hline Chronic blood loss anemia & 1.05 & 0.91 & 1.23 & 0.490 \\
\hline Chronic pulmonary disease & 1.07 & 1.04 & 1.11 & $<0.001$ \\
\hline Coagulopathy & 1.70 & 1.63 & 1.78 & $<0.001$ \\
\hline Congestive heart failure & 1.16 & 1.12 & 1.20 & $<0.001$ \\
\hline Deficiency anemias & 1.00 & 0.96 & 1.03 & 0.855 \\
\hline Depression & 0.90 & 0.86 & 0.95 & $<0.001$ \\
\hline
\end{tabular}




\section{Cureus}

\begin{tabular}{|c|c|c|c|c|}
\hline Diabetes with chronic complications & 0.97 & 0.92 & 1.03 & 0.357 \\
\hline Diabetes, uncomplicated & 1.01 & 0.98 & 1.04 & 0.568 \\
\hline Drug abuse & 0.95 & 0.82 & 1.10 & 0.487 \\
\hline Fluid and electrolyte disorders & 1.39 & 1.35 & 1.43 & $<0.001$ \\
\hline Hypertension & 0.96 & 0.92 & 0.99 & 0.013 \\
\hline Hypothyroidism & 0.95 & 0.92 & 0.99 & 0.020 \\
\hline Liver disease & 0.93 & 0.87 & 1.00 & 0.048 \\
\hline Lymphoma & 1.19 & 1.03 & 1.38 & 0.019 \\
\hline Metastatic cancer & 1.05 & 0.97 & 1.14 & 0.247 \\
\hline Obesity & 1.16 & 1.11 & 1.22 & $<0.001$ \\
\hline Peptic ulcer disease excluding bleeding & 1.22 & 0.88 & 1.68 & 0.235 \\
\hline Peripheral vascular disorders & 0.96 & 0.92 & 1.00 & 0.034 \\
\hline Psychoses & 0.81 & 0.74 & 0.90 & $<0.001$ \\
\hline Pulmonary circulation disorders & 1.06 & 0.98 & 1.14 & 0.135 \\
\hline Renal failure & 1.14 & 1.10 & 1.19 & $<0.001$ \\
\hline Rheumatoid arthritis/collagen vascular diseases & 1.03 & 0.94 & 1.11 & 0.553 \\
\hline Solid tumor without metastasis & 1.24 & 1.17 & 1.33 & $<0.001$ \\
\hline Valvular heart disease & 1.07 & 1.02 & 1.12 & 0.003 \\
\hline
\end{tabular}

\section{TABLE 4: Multivariable predictors of any complication in ERCP-related hospitalizations}

$\mathrm{P}<0.05$ indicates statistical significance.

The multivariable model was adjusted for demographics, hospital characteristics, and baseline comorbidities.

ERCP: endoscopic retrograde cholangiopancreatography; Cl: confidence interval; OR: odds ratio

\section{Discussion}

Cardiovascular morbidity, as well as mortality in patients undergoing endoscopic procedures with a recent history of acute coronary events, has been variable in different studies. There has been no consensus on their outcomes based on previous literature $[5,6]$. Overall, complications related to the endoscopy procedures have been reported to be the same in both the elderly and the young population [7]. However, most procedures, including EGD and colonoscopy, are relatively safer in patients having a risk of cardiovascular events when compared to ERCP [8]. The studies evaluating the safety and efficacy of ERCP in this patient population are scarce [9].

In our study, patients in Group 1 were older and had more pre-admission comorbidities when compared to patients in Group 2. A significantly higher prevalence of congestive heart failure (CHF) and hypertension in Group 1 patients can be traced to the low myocardial reserve as a result of the relevant cardiac events in the past. Thus, increased cardio-pulmonary complications, as well as inpatient mortality, could be multifactorial due to older age and other cardiovascular/ medical co-morbidities as evident from our multivariable regression analysis of predictors (Table 4). Patients after an acute coronary syndrome are advised to take an antiplatelet agent irrespective of the insertion of coronary stents, and most patients with a history of a PCI are on these medications. It can explain the higher incidence of hemorrhage in Group 1 patients, as some patients may not be able to come off these medications prior to the procedure. Sphincterotomy is an ERCP intervention with a relatively higher rate (up to $30 \%$ of cases with immediate bleeding) of post-ERCP bleeding and pancreatitis, which in turn can worsen the hypotension and increase the risk of myocardial ischemia [10]. Thus, it is advised to adhere to guidelines and consult cardiology for managing anticoagulation during ERCP in such patients [11].

Current literature lacks the practice trends with regards to the concern of increased mortality from ERCP in patients with a prior history of MI/PCI/CABG, which our study has addressed. We divided the available 
dataset into two groups of patients- one with a previous history of MI/PCI/CABG (Group 1, n=120,418) and one with no such prior history (Group 2, n=1,254,356). The results showed a rising trend of ERCP in patients with a previous history of MI/PCI/CABG from 2007 to 2014. It, however, did not result in increased inpatient mortality in such patients. Moreover, all-cause inpatient mortality was reduced from $1.8 \%$ in 2007 to $1.4 \%$ in 2014. The exact reason for this trend is not known but could be partly due to advancements in therapeutic endoscopy and appropriate rationalization of indications for which the procedure is being performed. As expected overall mortality in Group 1 was higher when compared to Group 2, which could be due to the multiple co-morbid statuses of these patients (1.7\% vs. $1.5 \%, \mathrm{p}<0.001)$.

Koh et al. retrospectively studied the complications of ERCP in 50 patients with a history of acute coronary syndrome, which also included $26 / 50$ patients with coronary stents [12]. The incidence of PEP was $12 \%$, and that of immediate bleeding was $14 \%$. There was one event of excessive post-ERCP delayed bleeding leading to cardiac ischemia and ultimately resulting in death. However, no other adverse cardiopulmonary complication was reported in any patient. In our study, 3.3\% and 3.9\% of patients who underwent ERCP had a history of PCI and CABG, respectively, and PEP occurred in $15.4 \%$ of patients in Group 2 . To our knowledge, it is the first study to report the incidence of post-ERCP pancreatitis in such a large number of patients with a history of PCI or CABG.

The biggest strength of our study was the sample size in both groups. Previous studies have lacked the assessment of the LOS and subsequent hospital charges. Our results show a higher mean LOS in Group 1 compared to Group 2 patients; however, it did not result in increased hospital charges. However, Group 1 patients were more likely to discharge to a skilled nursing/intermediate care facility or home health care possible because of older age, polypharmacy, and co-morbidities. We also performed a detailed multivariable regression analysis to identify predictors of complications in these patients.

Nojkov et al. previously reported on the outcomes of therapeutic ERCP in 19 patients in whom the procedure was conducted within 30 days of an acute attack of MI or unstable angina [13]. It was suggested that therapeutic ERCP could be safely performed for such patients within the first 30 days but preferably only for emergent indications and only after patient optimization. However, they recommended that diagnostic ERCP should be avoided as long as magnetic resonance cholangiopancreaticography (MRCP) can be performed in such patients.

Our study has a few limitations. Limitations associated with the NIS dataset precluded our ability to evaluate the outcomes by stratifying them based on the duration and association between cardiopulmonary events and the ERCP in Group 1 patients. It limits our understanding of the application of the results specific to patients who had ERCP $<30$ days or $>30$ days after MI/PCI/CABG. We also could not report laboratory values in these patients as well as recurrence of acute coronary syndrome during or post-ERCP as a separate outcome in these patients. It has been assessed by few retrospective studies in the past, which recommend monitoring the levels of troponin in such patients as it correctly identifies the ones at risk of having recurrent ischemia $[12,14]$.

\section{Conclusions}

In this nationwide retrospective analysis, we determined a rising trend in the utilization of ERCP procedures among patients with prior MI/PCI/CABG. Adult patients undergoing ERCP with a previous history of MI, PCI, or CABG had higher inpatient mortality, cardiopulmonary events, sepsis, and hemorrhage compared to those without this history. Future large prospective studies on outcomes of ERCP are warranted to define the impact of prior infarction or revascularization and timing prior to ERCP.

\section{Additional Information}

\section{Disclosures}

Human subjects: All authors have confirmed that this study did not involve human participants or tissue. Animal subjects: All authors have confirmed that this study did not involve animal subjects or tissue. Conflicts of interest: In compliance with the ICMJE uniform disclosure form, all authors declare the following: Payment/services info: All authors have declared that no financial support was received from any organization for the submitted work. Financial relationships: All authors have declared that they have no financial relationships at present or within the previous three years with any organizations that might have an interest in the submitted work. Other relationships: All authors have declared that there are no other relationships or activities that could appear to have influenced the submitted work.

\section{Acknowledgements}

Harsh K. Patel and Rupak Desai contributed equally to the manuscript.

\section{References}

1. Dorreen A, Moosavi S, Martel M, Barkum AN: Safety of digestive endoscopy following acute coronary syndrome: a systematic review. Can J Gastroenterol Hepatol. 2016, 2016:9564529. 10.1155/2016/9564529 
2. Freeman ML: Adverse outcomes of endoscopic retrograde cholangiopancreatography. Rev Gastroenterol Disord. 2002, 2:147-168. 10.1016/S1052-5157(03)00107-7

3. HCUP databases. (2019). Accessed: November 5, 2019: https://www.hcup-us.ahrq.gov/overview.jsp.

4. Inamdar S, Sejpal DV, Ullah M, Trindade AJ: Weekend vs. weekday admissions for cholangitis requiring an ERCP: comparison of outcomes in a national cohort. Am J Gastroenterol. 2016, 11:405-410. 10.1038/ajg.2015.425

5. Cappell MS: Safety and clinical efficacy of flexible sigmoidoscopy and colonoscopy for gastrointestinal bleeding after myocardial infarction: a six-year study of 18 consecutive lower endoscopies at two university teaching hospitals. Dig Dis Sci. 1994, 39:473-480. 10.1007/BF02088330

6. Spier BJ, Said A, Moncher K, Pfau PR: Safety of endoscopy after myocardial infarction based on cardiovascular risk categories: a retrospective analysis of 135 patients at a tertiary referral medical center. J Clin Gastroenterol. 2007, 41:462-467. 10.1097/01.mcg.0000225624.91791.fa

7. Köklü S, Parlak E, Yüksel O, Sahin B: Endoscopic retrograde cholangiopancreatography in the elderly: a prospective and comparative study. Age Ageing. 2005, 34:572-577. 10.1093/ageing/afi180

8. Rosenberg J, Jorgensen LN, Rasmussen V, Vibits H, Hansen PE: Hypoxaemia and myocardial ischaemia during and after endoscopic cholangiopancreatography: call for further studies. Scand J Gastroenterol. 1992, 27:717-720. 10.3109/00365529209000147

9. Cappell MS: Endoscopic retrograde cholangiopancreatography with endoscopic sphincterotomy for symptomatic choledocholithiasis after recent myocardial infarction. Am J Gastroenterol. 1996, 91:18271831.

10. Szary NM, Al-Kawas FH: Complications of endoscopic retrograde cholangiopancreatography: how to avoid and manage them. Gastroenterol Hepatol (N Y). 2013, 9:496-504.

11. Anderson MA, Ben-Menachem T, Gan SI, et al.: Management of antithrombotic agents for endoscopic procedures. Gastrointest Endosc. 2009, 70:1060-1070. 10.1016/j.gie.2009.09.040

12. Koh HR, Park CH, Chung MW, et al.: Endoscopic retrograde cholangiopancreatography in patients with previous acute coronary syndrome. Gut Liver. 2014, 8:674-679. 10.5009/gnl13301

13. Nojkov B, Cappell MS: Safety and efficacy of ERCP after recent myocardial infarction or unstable angina . Gastrointest Endosc. 2010, 72:870-880. 10.1016/j.gie.2010.06.024

14. Fisher L, Fisher A, Thomson A: Cardiopulmonary complications of ERCP in older patients . Gastrointest Endosc. 2006, 63:948-955. 10.1016/j.gie.2005.09.020 